\title{
MONOTONE TRANSFORMATIONS ON $B(H)$ WITH RESPECT TO THE LEFT-STAR AND THE RIGHT-STAR PARTIAL ORDER
}

\author{
Gregor Dolinar, Alexander Guterman and Janko Marovt
}

Abstract. Let $H$ be an infinite dimensional complex Hilbert space, and let $B(H)$ be the set of all bounded linear operators on $H$. In the paper equivalent definitions for the left-star and the right-star partial orders on $B(H)$ are given and bijective additive maps on $B(H)$ which preserve the left-star or the right-star partial order in both directions are characterized.

Mathematics subject classification (2010): 06A06, 15A03, 15A04, 15A86.

Keywords and phrases: Star partial order, minus partial order, left-star partial order, right-star partial order, preserver.

\section{REFERENCES}

[1] J. K. Baksalary, S. K. Mitra, Left-star and right-star partial orderings, Linear Algebra Appl. 149 (1991), 73-89.

[2] M. P. DraZIN, Natural structures on semigroups with involution, Bull. Amer. Math. Soc. 84 (1978), $139-141$.

[3] G. Dolinar, A. Guterman, J. Marovt, Automorphisms of $K(H)$ with respect to the star partial order, Operators and Matrices 7 (2013), No. 1, 225-239.

[4] G. Dolinar, J. Marovt, Star partial order on B(H), Linear Algebra Appl. 434 (2011), 319-326.

[5] P. A. Fillmore, W. E. LongSTAFF, On isomorphisms of lattices of closed subspaces, Can. J. Math. 5 (1984), 820-829.

[6] A. E. Guterman, Monotone additive transformations on matrices, Mat. Zametki, 81 (2007), 681692.

[7] R. E. HARTwig, How to partially order regular elements, Math. Japon. 25 (1980), 1-13.

[8] X. LiU, J. BeníteZ, J. ZhONG, Some results on partial ordering and reverse order law of elements of $C^{*}$-algebras, J. Math. Anal. Appl. 370 (2010), 295-301.

[9] S. K. Mitra, P. Bhimasankaram, S. B. Malik, Matrix partial orders, shorted operators and applications, Word Scientific, London, 2010.

[10] L. Molnar, A. Kovacs, An extension of a characterization of the automorphisms of Hilbert space effect algebras, Rep. Math. Phys. 52 (2003), 141-149.

[11] M. Z. NASHED (ed.), Generalized inverses and applications, Academic Press, New York-London, 1976.

[12] R. Penrose, A generalized inverse for matrices, Proc. Cambridge Phil. Soc. 51 (1955), 406-413.

[13] S. Roch, B. Silbermann, $C^{*}$-algebra techniques in numerical analysis, J. Operator Theory 35 (1996), 241-280.

[14] P. ŠEMrL, Automorphisms of B(H) with respect to minus partial order, J. Math. Anal. Appl. 369 (2010), 205-213. 